\title{
Controlled trial of budesonide given by the Nebuhaler in preschool children with asthma
}

\author{
J G A Gleeson, J F Price
}

\begin{abstract}
Objective-To determine whether the inhaled corticosteroid budesonide, given by a Nebuhaler spacing device, was effective in prophylaxis of asthma in preschool children.

Design-Double blind, placebo controlled, random order crossover trial with two week practice run in period.
\end{abstract}

Setting-Outpatient clinic referrals in secondary referral centre.

Patients - 39 children aged 2-6 years selected for the following: able to use Nebuhaler; parents able to complete record card; poorly controlled asthma (defined); not already on systemic or inhaled steroids. Eleven withdrew for various reasons not connected with intolerance to budesonide. Age, sex, other atopies, and symptoms during run in period were similar in the 28 children who completed the trial and in the 11 who withdrew.

Interventions-Budesonide $200 \mu \mathrm{g}$ or placebo (both one puff) given twice daily during 6-week treatment or control periods, using Nebuhaler after prior training. Three week "washout" at crossover. Compliance monitored by weighing canisters. Patients withdrawn if their acute attacks required treatment with systemic steroids.

End point -Control of asthma.

Measurements and main results-Peak expiratory flow rate measured twice daily where cooperation allowed. Diary of symptoms and concomitant drug use kept daily. Results showed mean peak flow significantly higher $(12 \%$ in mornings, $14 \%$ in evenings $)$ in second three weeks of intervention compared with control period $(95 \%$ confidence intervals $6 \cdot 3-17 \cdot 3 \%$

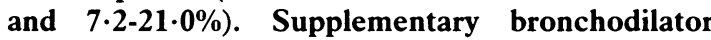
drugs reduced by $50 \%$ during intervention periods.

Conclusions-Budesonide given by Nebuhaler is effective prophylaxis for preschool children with frequent asthma.

\section{Introduction}

Prophylaxis against asthma in preschool children is difficult. Slow release theophylline given orally may be beneficial, ' but compliance is poor and side effects are common. ${ }^{2}$ The other orally active agent, ketotifen, has proved ineffective in young children with asthma. Children under 5 years cannot use unmodified metered dose aerosols and have difficulty using powder inhalers correctly. Sodium cromoglycate by nebuliser may benefit some children but is tedious and time consuming to give.

The efficacy of inhaled corticosteroids given by pressurised aerosol or by powder inhaler is well established in older children, ${ }^{5-7}$ but only two placebo controlled trials have been done in preschool children with asthma, both of nebulised beclomethasone dipropionate. They showed either marginal ${ }^{*}$ or no benefit ${ }^{\circ}$ from the nebulised suspension of this inhaled steroid.

Trials of a comparatively new inhaled corticosteroid, budesonide, have indicated that it is at least as effective as beclomethasone in older children ${ }^{1011}$ and can be given by the Nebuhaler, a $750 \mathrm{ml}$ pear shaped spacer device with a one way valve (Astra). In previous studies we showed that a simple method of taking five breaths sufficient to move the one way valve after actuation of the canister containing the drug was an effective way to give treatment for asthma with the Nebuhaler and can be achieved by nearly all children from the age of 2 years. ${ }^{1213}$ We therefore conducted a placebo controlled trial of budesonide inhaled with the Nebuhaler in preschool children with asthma.

\section{Patients and methods}

We obtained informed parental consent, and the trial was approved by the hospital's ethical committee.

Patients-Children aged 2 to 6 years who could use a Nebuhaler and whose parents could reliably fill in a daily record card were selected if their asthma was poorly controlled (at least one attack a month in each of the previous three months or symptoms on most days, or both). Children were excluded if they were already taking steroids systemically or by inhalation or if they had received a short course of corticosteroids systemically during the previous four weeks. Thirty nine children ( 26 boys and 13 girls) aged $26-71$ months (median 51 months) entered the study. All had perennial asthma, which dated from infancy in 21 children. Fifteen children also had eczema and eight had allergic rhinitis. One child taking nebulised sodium cromoglycate, 11 theophylline, and 13 regular $\beta$ agonists continued taking these drugs in a fixed dosage throughout the study. The parents of each child were asked to give extra doses of bronchodilator whenever necessary throughout the trial.

Design of trial-The trial was preceded by a two week run in when the children practised using the Nebuhaler. The severity of asthma was documented, and the parents' ability to keep daily record cards was assessed. The trial was a double blind, crossover design with budesonide $200 \mu \mathrm{g}$ (one puff) or placebo given twice daily with the Nebuhaler; placebo and budesonide were given in random order each for six weeks. The medicines for the trial were in identical canisters. The technique of inhalation of five breaths of sufficient size to trigger the Nebuhaler's valve ${ }^{12}$ was used to give each dose of trial medicine. The two periods of treatment were separated by a washout phase of three weeks, when the children continued to take their usual drugs. Acute asthma attacks that did not respond to treatment with bronchodilators were treated with systemic corticosteroids and the child was withdrawn but allowed to re-enter provided that at least four weeks had elapsed after completing the course of steroids.
Correspondence to: Dr J F Price, Department of Child Health, King's College Hospital, London SE5 9RS 
Evaluation of patients-The parents were asked to keep a daily record on diary cards of $(a)$ morning and evening peak expiratory flow rates, which were recorded three times before treatment if the child could use a Wright peak flow minimeter; $(b)$ all drugs given; and $(c)$ symptoms, which were cough and wheeze at night, daytime cough, daytime wheeze, and breathlessness on exertion and were allocated a score of 0 to 3 . The children were seen every three weeks and on demand during the trial. At each visit they were examined, their technique in using the Nebuhaler was checked, compliance was monitored by weighing the trial canister, and diary cards were reviewed.
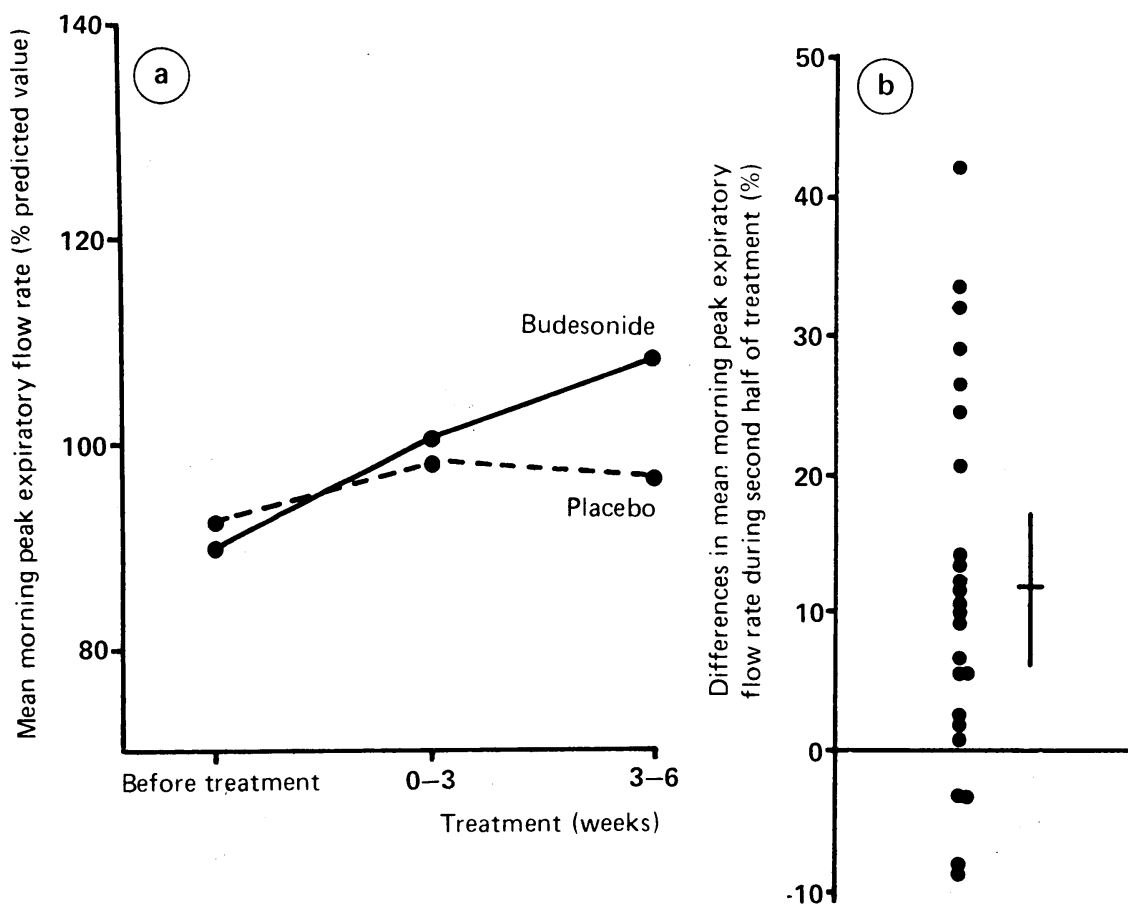

FIG 1-(a) Mean morning peak expiratory flow rate in 25 children before and during each treatment. (b) Individual differences between treatment with budesonide and placebo in mean morning peak expiratory flow rate during second three weeks of treatment. Vertical bar shows mean and $95 \%$ confidence interval
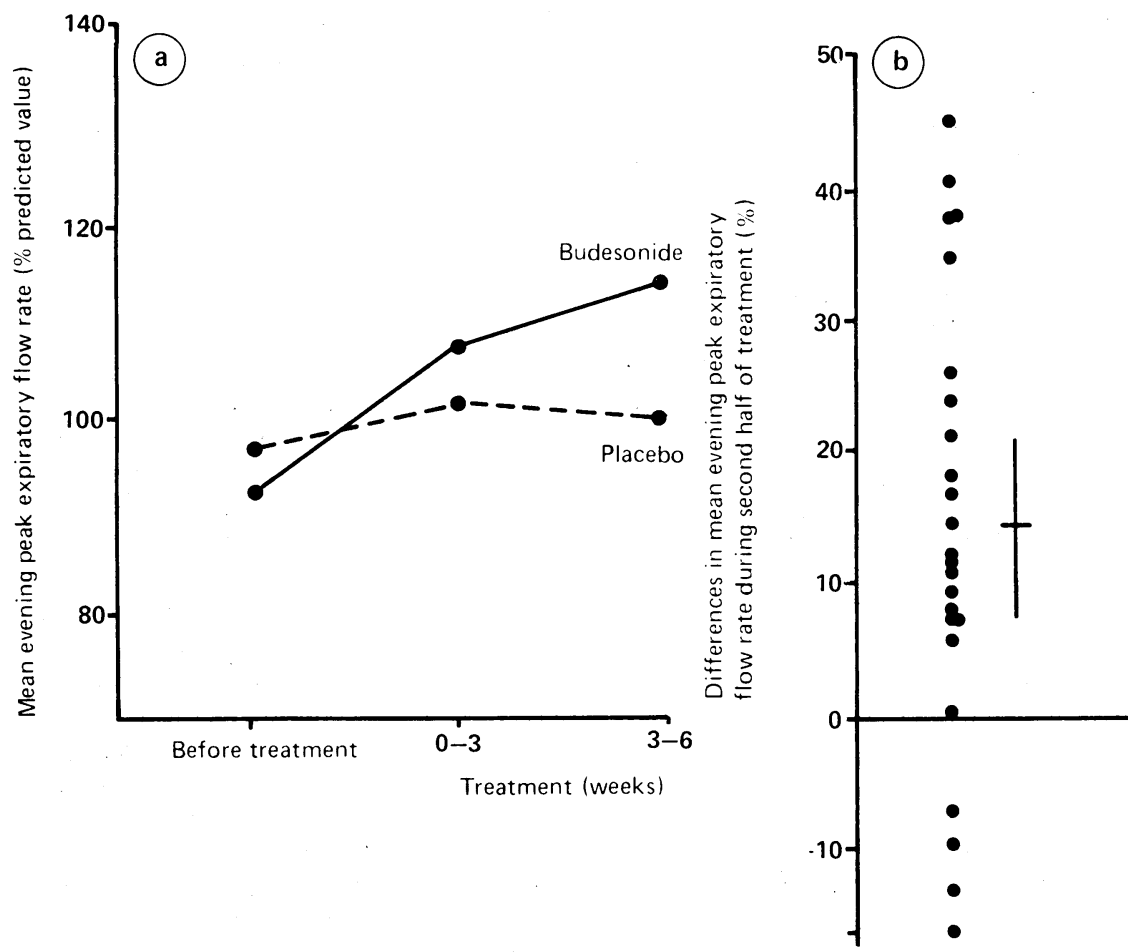

FIG 2-(a) Mean evening peak expiratory flow rate in 25 children before and during each treatment. (b) Individual differences between treatment with budesonide and placebo in mean evening peak expiratory flow rate during second three weeks of treatment. Vertical bar shows mean and $95 \%$ confidence interval
At the end of each period of treatment the children were assessed in the laboratory between 8 am and $10 \mathrm{am}$; the trial drug was not given that morning and no bronchodilator was inhaled for at least two hours. Peak expiratory flow rate was recorded (best of three values) before taking $500 \mu \mathrm{g}$ of terbutaline with the Nebuhaler and 10 minutes afterwards. Blood was taken for estimation of plasma cortisol concentration and counts of eosinophils and neutrophils. During the trial any possible side effects were recorded.

Analysis - The data were analysed with independent and paired $t$ tests, and crossover analysis was performed according to the guidelines given by Pocock for this type of trial. ${ }^{1+}$ As prophylactic drugs given before the trial were not discontinued during it only the extra doses of bronchodilator (score of 1 per dose) were used to calculate the score for concomitant drug treatment. The best of the three recordings of peak expiratory flow rate at each time was used in the analysis, all such data being expressed as percentages of predicted normal values. ${ }^{15} 16$ Average daily morning and evening peak expiratory flow rates and scores for concomitant drug treatment and symptoms were calculated for the two week run in, the first three weeks of treatment, the second three weeks of treatment, and the three week washout. The results in the two groups were analysed separately (group 1, treatment with budesonide then placebo; group 2, treatment with placebo then budesonide) and overall effects of treatment and carry over calculated. If carry over effects were significant $(p<0 \cdot 1)$ for any variable, the variable was analysed in a parallel group fashion in only the first period of treatment.

\section{Results}

Twenty eight children completed the trial satisfactorily. Five were withdrawn because of acute asthma attacks, for which they were admitted to hospital and given corticosteroids systemically; one of these children was withdrawn on day 8 of treatment with budesonide and the four others were withdrawn on days $14,26,37$, and 42 of treatment with placebo. One child was withdrawn during treatment with budesonide because of poor compliance as judged by the canister's weight loss. Five children failed to keep follow up appointments, three while taking placebo and two while taking budesonide. Four of these children have since been traced, and their withdrawal was for social reasons unrelated to the trial. The characteristics of those who completed the study and those who did not were similar in terms of age, distribution of sex, concomitant atopic disorders, and symptoms recorded on diary cards during the run in period.

\section{OBJECTIVE ASSESSMENT}

Diary card records of peak expiratory flow rate were kept by the parents of 25 of the 28 children who completed the study. Morning and evening peak expiratory flow rates were similar before each period of treatment (mean difference in morning peak expiratory flow rate $2 \%$ and in evening peak expiratory flow rate $4 \% ; p>0 \cdot 1)$. Peak expiratory flow rates recorded on diary cards tended to rise during the first three weeks of both treatments. During the second three weeks of treatment morning and evening peak expiratory flow rates were significantly higher with budesonide than with placebo $(p=0.0001$ for mean morning peak expiratory flow rate, $p=0.0004$ for the mean evening peak expiratory flow rate). The mean difference between treatment with budesonide and placebo in the mean morning peak expiratory flow rate during the second three weeks of treatment was $12 \%$ (95\% confidence interval 6.3 to $17 \cdot 3 \%$ ) and that in the 


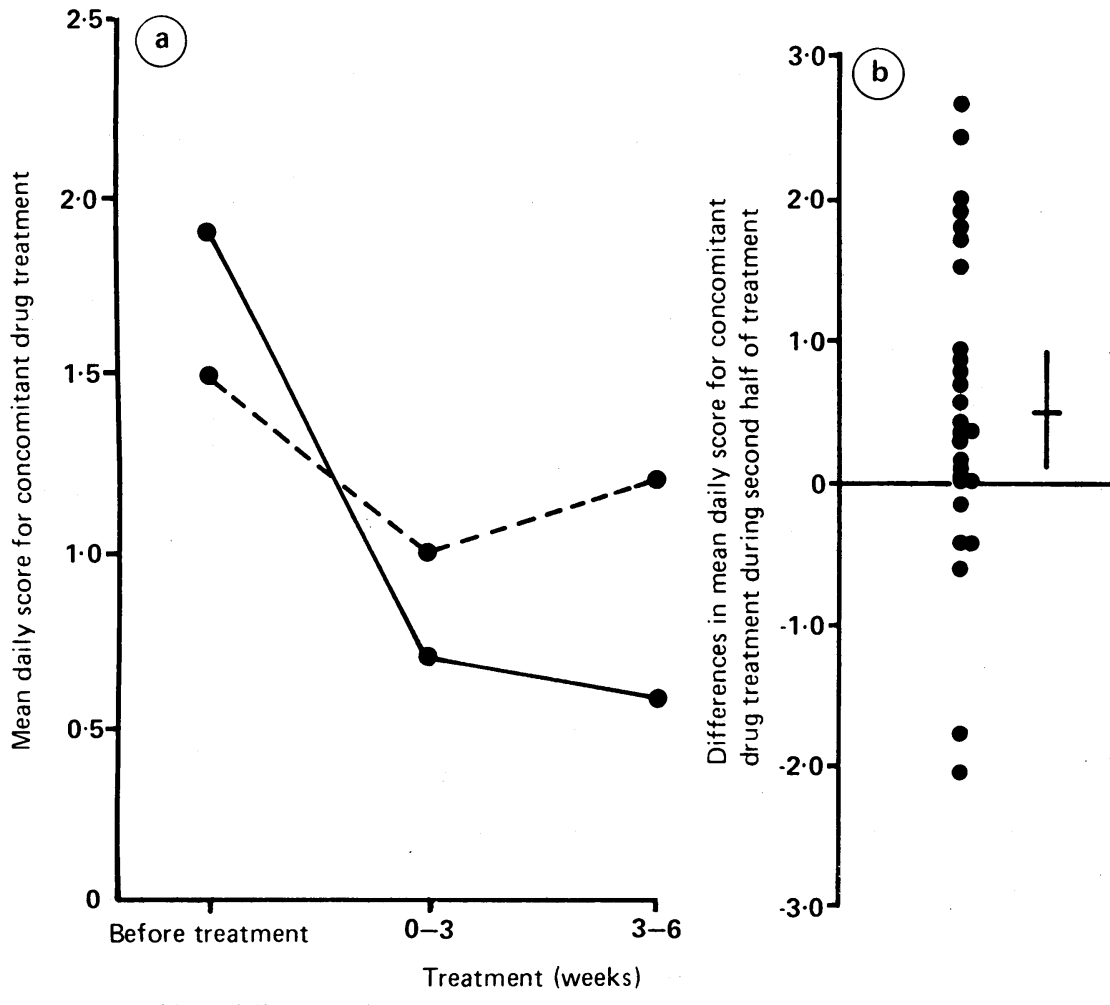

FIG 3- (a) Mean daily scores for concomitant drug treatment in 28 children before and during each treatment. (b) Individual differences between treatment with budesonide and placebo in mean daily score for concomitant drug treatment during second half of treatment. Vertical bar shows mean and $95 \%$ confidence interval

mean evening peak expiratory flow rate $14 \%(95 \%$ confidence interval $7 \cdot 2$ to $21 \cdot 0 \%$ ) (figs 1 and 2 ). The analysis did not show any order or carry over effect.

The responsiveness to bronchodilators as measured by the change in peak expiratory flow rate 10 minutes after inhaling terbutaline was the same after six weeks of treatment with budesonide (mean change $16 \%$ ) and six weeks of treatment with placebo (mean change $17 \%$ ). Peak expiratory flow rates after treatment with budesonide, however, were higher (mean $112 \%$ ) than those after placebo (mean $101 \%$ ), the mean difference being $12 \%$ ( $95 \%$ confidence interval 1.6 to $22.0 \%$; $\mathrm{p}<0.05$ )

\section{SUBJECTIVE ASSESSMENT}

During the last three weeks of treatment with budesonide the need for additional treatment with bronchodilators was about half that required during the last three weeks of treatment with placebo $(p=$ 0.0221 ). The mean difference between treatment with budesonide and placebo in the mean daily score for concomitant drug treatment was $0.52(95 \%$ confidence

TABLE I-Mean (SEM) daily scores of symptoms during second three weeks of each treatment in 28 children

\begin{tabular}{lcc}
\hline & \multicolumn{2}{c}{ Treatment } \\
\cline { 2 - 3 } & Placebo & Budesonide \\
\hline Nocturnal cough and wheeze & $0 \cdot 48(0.08)$ & $0 \cdot 35(0.08)$ \\
Daytime cough & $0 \cdot 48(0.07)$ & $0 \cdot 36(0.09)$ \\
Daytime wheeze & $0 \cdot 22(0.06)$ & $0 \cdot 13(0.04)$ \\
Breathlessness on exertion & $0 \cdot 26(0.09)$ & $0 \cdot 15(0.05)$ \\
\hline
\end{tabular}

TABLE II-Mean (SEM) plasma cortisol concentrations and eosinophil and neutrophil counts at end of each treatment in 28 children

\begin{tabular}{lrr}
\hline & \multicolumn{2}{c}{ Treatment } \\
\cline { 2 - 3 } & \multicolumn{1}{c}{ Placebo } & \multicolumn{1}{c}{ Budesonide } \\
\hline Early morning cortisol $(\mathrm{nmol} / \mathrm{l})$ & $231(17)$ & $260(21)$ \\
Eosinophil count $\left(\times 10^{6} / \mathrm{l}\right)$ & $643(108)$ & $616(110)$ \\
Neutrophil count $\left(\times 10^{6} / 1\right)$ & $3123(394)$ & $3148(315)$ \\
\hline
\end{tabular}

interval 0.09 to 0.95 ) (fig 3). Daily scores for symptoms were similar before each period of treatment. The mean values for each symptom favoured budesonide during the second three weeks of treatment but none reached significance at the $5 \%$ level (table I). Nocturnal cough and wheeze had a significant carry over effect, and when these symptoms were analysed in a parallel group fashion for the first period of treatment alone they were significantly higher with placebo, the mean difference being 0.38 ( $95 \%$ confidence interval 0.11 to $0.65 ; \mathrm{p}<0.01$ ).

Adverse effects-No differences were found in early morning plasma cortisol concentrations and eosinophil and neutrophil counts at the end of six weeks of treatment with budesonide and placebo (table II). Two patients complained that the trial medicine made them cough; in one the cough was more severe with placebo and in the other it occurred only with placebo.

\section{Discussion}

This trial indicates that budesonide inhaled twice daily by means of the Nebuhaler is beneficial to preschool children with moderately severe perennial asthma. The beneficial effect was most apparent from peak expiratory flow rates measured at home and recorded on diary cards. Many of the children achieved quite high flow rates even on entering the study, when the control of asthma was poor, and the average morning and evening flow rates towards the end of the treatment with budesonide were well above predicted values. This apparent discrepancy has been noted in previous studies. ${ }^{1718}$ Peak expiratory flow rate depends on effort and most of our patients were well trained and probably had better developed accessory muscles of respiration than the children on whom the data for normal subjects are based. The optimal peak expiratory flow rate for a child with asthma may well be on average higher than that for a child without asthma, particularly if the child without asthma performs the test on a single occasion for the purpose of obtaining data on normal children.

Corticosteroids may enhance adrenergic responsiveness and increase the bronchodilator action of $\beta$ agonists, ${ }^{19}$ although clinical trials have failed to confirm this effect. ${ }^{2021}$ We tried to study the effects of a single dose of bronchodilator at the end of both periods of treatment, but the much higher values after treatment with budesonide before inhaling terbutaline almost certainly invalidate any comparison of responsiveness to bronchodilator drugs.

Several possible reasons exist to explain why the observed improvement in lung function was not matched by a similar reduction in recorded symptoms. Inaccurate estimation of the severity of asthma is common and the discrepancy between objective and subjective assessments is probably greater in young children as they often do not complain of symptoms and doctors rely on their parents' perception of their asthma. ${ }^{22}$ This view is supported by a recent nocturnal study of children with asthma in which the number of coughs from a tape recording (objective assessment) correlated poorly with the number recorded on a diary card..$^{23}$ We used a scale of $0-3$ to assess symptoms; others have used wider ranges or visual analogue scales and it may be that our scoring system was not sufficiently discriminatory. We continued other forms of prophylactic treatment without changing the dose during the trial but asked parents to give additional doses of a bronchodilator when necessary. Notably, parents gave significantly more bronchodilator when the child was receiving placebo, implying that the control of asthma was not as good as the scores for symptoms suggested.

An important aspect of prophylaxis is preventing 
severe attacks of asthma. In the study by Storr et al many children were withdrawn for medical reasons, but nebulised beclomethasone did not reduce the number of children withdrawn. ${ }^{8}$ Withdrawals from our study because of acute attacks of asthma requiring treatment with systemic corticosteroids were uncommon but more often seen during treatment with placebo. The one child who was withdrawn while taking budesonide had completed only one week of treatment. Although budesonide improves pulmonary function fairly rapidly, ${ }^{20}$ its beneficial effects on asthma induced by exercise ${ }^{21}$ and in preventing the immediate allergic reaction ${ }^{24}$ take some time to develop. Perhaps one week's treatment with budesonide is insufficient to prevent severe attacks of asthma.

The difference in efficacy of budesonide aerosol with the Nebuhaler and beclomethasone suspension with the nebuliser probably lies in the mode of presentation rather than in any fundamental difference between the drugs. In vitro studies and clinical trials with similar routes of administration suggest that these two inhaled steroids are similar in their action. ${ }^{1011}$ The Nebuhaler is a comparatively cheap and convenient way to give drugs and after a short tuition period most preschool children can manage the inhalation technique we have described under parental supervision. The average age of the children in our trial was just over 4 years, which accounts for the high proportion of children who were able to give reproducible peak expiratory flow rates. In our experience nearly all 3 year old children of average intelligence can master the technique we have described for the Nebuhaler. We studied comparatively few children under the age of 3 years but have found in this and in a previous study ${ }^{13}$ that, with patience, many children even this young can be taught to use the Nebuhaler effectively.

The absence of oropharyngeal complications in our study is not surprising as spacers diminish the amount of drug deposited there. ${ }^{25}$ The systemic effects of budesonide may be largely due to its absorption from the distal non-ciliated airways and alveoli ${ }^{26}$ because any active drug swallowed and absorbed from the gut is largely inactivated on its first pass through the liver. ${ }^{27}$ In adults with asthma the drug's effect is dependent on dose and is to raise the neutrophil count and lower the eosinophil count and early morning cortisol concentrations, ${ }^{26}$ implying some systemic effect with high doses of treatment. That our results showed improved pulmonary function without such evidence of absorption of corticosteroid systemically is reassuring and suggests preferential or at least predominant deposition in the conducting airways where inhaled corticosteroids are thought to act, ${ }^{28}$ rather than in the periphery of the lung. We did not test hypothalmopituitary-adrenal function in our patients, but the results of tests with tetracosactrin in older children taking similar ${ }^{1021}$ and larger ${ }^{29}$ doses of budesonide have been reassuring. A recent study of children with asthma found that beclomethasone reduces nocturnal cortisol secretion and early morning cortisol concentrations, these effects being dependent on dose. ${ }^{30}$ In older children long term use of regularly inhaled corticosteroids has not produced clinically important systemic effects. ${ }^{31-33}$ We used a comparatively high dose of budesonide and its potential for systemic corticosteroid effects in preschool children needs to be assessed for longer. In practice we suggest using as low a dose as possible of budesonide to control asthma.

We conclude that budesonide given by the Nebuhaler is beneficial for preschool children with asthma who need prophylaxis in that it improves pulmonary function and reduces the need for concomitant treatment with bronchodilators.

We thank the children and parents who participated, Ms Jenny Pool for her help in the pulmonary function laboratory, and Ms Kerry Jones for typing the manuscript. We also thank the Department of Probability and Statistics, University of Sheffield, for statistical advice and Astra Pharmaceuticals Ltd for supplying the preparations used in the trial. JGAG is supported by a grant from the Children Nationwide Medical Research Fund.

1 Stratton D, Carswell F, Hughes AD, Fysh WJ, Robinson P. Double-blind comparisons of slow-release theophylline, ketotifen and placebo and prophylaxis of asthma in young children. $B r$ f Dis Chest 1984;78:163-7.

2 Loftus BG, Price JF. Treatment of asthma in preschool children with slow release theophylline. Arch Dis Child 1985;60:770-2.

3 Loftus BG, Price JF. Long-term placebo-controlled trial of ketotifen in the management of preschool children with asthma. I Allergy Clin Immunol 1987;79:350-5.

4 Cogswell JJ, Simpkiss MJ. Nebulised sodium cromoglycate in recurrently wheezy preschool children. Arch Dis Child 1985;60:736-8.

5 Godfrey S, Konig P. Treatment of childhood asthma for 13 months and longer with beclomethasone dipropionate aerosol. Arch Dis Child 1974;49:591-6.

6 Klein R, Waldman D, Kershnar H, et al. Treatment of chronic childhood asthma with beclomethasone dipropionate aerosol: a double-blind crossover trial in non-steroid-dependent patients. Pediatrics 1977;60:7-13.

7 Edmunds AT, McKenzie S, Tooley M, Godfrey S. A clinical comparison of beclomethasone dipropionate delivered by pressurised aerosol and as a powder from a rotahaler. Arch Dis Child 1979;54:233-5.

8 Storr J, Lenney CA, Lenney W. Nebulised beclomethasone dipropionate in preschool asthma. Arch Dis Child 1986;61:270-3.

9 Webb MSC; Milner AD, Hiller EJ, Henry RL. Nebulised beclomethasone dipropionate suspension. Arch Dis Child 1986;61:1108-10.

10 Field HV, Jenkinson PMA, Frame MH, Warner JO. Asthma treatment with new corticosteroid aerosol, budesonide, administered twice daily by spacer inhaler. Arch Dis Child 1982;57:864-6.

11 Baran D. A comparison of inhaled budesonide and beclomethasone dipropionate in childhood asthma. Br 7 Dis Chest 1987;81:170-5.

12 Gleeson JGA, Price JF Nebuhaler technique Br 7 Dis Chest 1988;82:172-4.

13 Pool JB, Greenough A, Gleeson JGA, Price JF. Inhaled bronchodilator therapy via the nebuhaler in young asthmatics. Arch Dis Child 1988;63: 288-91.

14 Pocock SJ. Clinical trials: a practical approach. New York: Wiley, 1983.

15 Milner AD, Ingram D. Peak expiratory flow rates in children under 5 years of age. Arch Dis Child 1970;45:780-2.

16 Cogswell JJ, Hull D, Milner AD, Norman AP, Taylor B. Lung function in childhood. III. Measurement of airflow resistance in healthy children. $\mathrm{Br} \mathcal{J}$ Dis Chest 1975; 69:177-87.

17 Wilson N, Silverman M. Controlled trial of slow-release aminophylline in childhood asthma: are short-term trials valid? $\mathrm{Br}$ Med $\mathcal{f}$ 1982;284:863-6.

18 Edmunds AT, Carswell F, Robinson P, Hughes AO. Controlled trial of cromoglycate and slow-release aminophylline in perennial childhood asthma. BrMed f 1980;281:842.

19 Ellul-Micallef R, Fenech FF. Effects of intravenous prednisolone in asthmatics with diminished adrenergic responsiveness. Lancet 1975; ii: 1269-71.

20 Dahl R, Johansson S-A. Effect on lung function of budesonide by inhalation, terbutaline sc and placebo given simultaneously or as single treatments. $E$, f Respir Dis [Suppl] 1982;122:132-7.

21 Henriksen JM, Dahl R. Effects of inhaled budesonide alone and in combination with low-dose terbutaline in children with exercise-induced asthma. Am Rev Respir Dis 1983;128:993-7.

22 Sly PD, Landau LI, Weymouth R. Home recording of peak expiratory flow rates and perception of asthma. Am $\mathcal{J}$ Dis Child 1985;139:479-82.

23 Archer LNJ, Simpson H. Night cough counts and diary card scores in asthma. Arch Dis Child 1985;60:474-5.

24 Dahl R, Johansson S-A. Importance of duration of treatment with inhaled budesonide on the immediate and late bronchial reaction. Eur $\mathcal{f}$ Respir $D i$ [Suppl] 1982;122:167-75.

25 Newman SP, Moren F, Pavia D, Little F, Clarke SW. Deposition of pressurised suspension aerosols inhaled through extension devices. Am Rev Respir Dis 1981;124:317-20.

26 Toogood JH, Baskerville J, Jennings B, Lefcoe NM, Johansson S. Use of spacers to facilitate inhaled corticosteroid treatment of asthma. Am Rev Respir Dis 1984;129:723-9.

27 Ryrfeldt A, Anderson P, Edsbacker S, Tonnesson M, Davies D, Pauwels R. Pharmacokinetics and metabolism of budesonide, a selective glucocorticoid. Eur f Respir Dis 1982;63(suppl 122):86-95.

28 Williams MH Jr. Drugs five years after: beclomethasone dipropionate. An Intern Med 1981;95:464-7.

29 Kerrebijn KF, Van Essen-Zandvliet EEM, Neijens HJ. Effect of long-term treatment with inhaled corticosteroids and beta-agonists on the bronchial responsiveness in children with asthma. $\mathcal{F}$ Allergy Clin Immunol 1987;79: 653-9.

30 Law CM, Marchant JL, Honour JW, Preece MA, Warner JO. Nocturna adrenal suppression in asthmatic children taking inhaled beclomethasone dipropionate. Lancet 1986;i:942-4.

31 Balfour-Lynn L. Growth and childhood asthma. Arch Dis Child 1986;61: 1049-51.

32 Brown HM, Bhowmik M, Jackson FA, Thantrey N. Beclomethasone dipropionate aerosols in the treatment of asthma in childhood. Practitioner $1980 ; 224: 847-51$.

33 Smith JM. Inhaled steroids in the management of childhood asthma: including data from a longterm follow-up of a large, personal series. In: Clark TJH, ed. Steroids in asthma: a reappraisal in the light of inhalation therapy. Auckland: ADIS Press, 1983:193-209.

(Accepted 7 April 1988 